\title{
CORRESPONDENCE
}

\section{Drug Therapy in Patients With Chronic Renal Failure}

by Dr. med. Bertram Hartmann, PD Dr. med. David Czock,

Prof. Dr. med. Frieder Keller in volume 37/2010

\section{Anticoagulation in Renal Failure Is Safe and Effective}

Hartmann et al presented important principles of drug therapy in patients with renal failure. However, concrete individual recommendations regarding anticoagulation given in the article have to be corrected. Uremic bleeding disorder simultaneously combines bleeding risk with procoagulatory activity and increased risk of thrombosis. Especially patients with severe renal failure (GFR $<30 \mathrm{~mL} / \mathrm{min}$ ) present with increased cardiovascular morbidity and mortality. Then any type of anticoagulation incurs an increased risk of hemorrhage and requires critical selection of the anticoagulatory drug using appropriate dosage and laboratory monitoring. Patients with severe renal failure are usually not represented in study populations, even for the newer oral anticoagulants.

Low molecular weight heparins have notably improved the options for anticoagulation compared with unfractionated heparin and vitamin $\mathrm{K}$ antagonists. The articles' conclusion, not to use enoxaparin in patients with GFR $<60 \mathrm{~mL} / \mathrm{min}$, is wrong. Enoxaparin is the low molecular weight heparin that has been most extensively studied for all stages of renal failure and is explicitly licensed for a GFR $<30 \mathrm{~mL} / \mathrm{min}$ with clear recommendations how to adapt the dosage. Suggesting tinzaparin as an alternative in this context is not reasonable.

As assessed by permeation chromatography, enoxaparin is the low molecular weight heparin with the highest content of defined oligomers, whereas tinzaparin to a substantial extent resembles unfractionated heparin (1). The wording of accumulation "in a deep compartment" in the article remains an enigma. In acute coronary syndrome, using enoxaparin yields a mortality advantage without increasing hemorrhageassociated complications, even in severe renal failure $(2,3)$. Mahe et al did not observe more hemorrhagic complications in the referenced study for enoxaparin than for tinzaparin, although the dosage of enoxaparin had not been adequately adjusted in some cases and not adapted according to laboratory monitoring.

The IRIS study investigated tinzaparin versus unfractionated heparin in venous thrombosis and found a higher mortality for tinzaparin in patients with renal failure who were older than 70 .

DOI: 10.3238/arztebl.2011.0112a

\section{REFERENCES}

1. Bisio A, Vecchietti D, Citterio L, et al.: Structural features of low-molecular-weight heparins affecting their affinity to antithrombin. Thromb Haemost 2009; 102: 865-73.

2. Collet JP, Montelascot G, Agnelli G, et al.: Non-ST-segment elevation acute coronary syndrome in patients with renal dysfunction: benefit of low-molecular-weight heparin alone or with glycoprotein Ilb/llla inhibitors on outcomes. The global registry of acute coronary events. Eur Heart J 2005; 26: 2285-93.

3. Spinler SA, Inverso SM, Cohen M, Goodman SG, Stringer KA, Antman EM; ESSENCE and TIMI 11B Investigators: Safety and efficacy of unfractionated heparin versus enoxaparin in patients who are obese and patients with severe renal impairment: analysis from the ESSENCE and TIMI 11B studies. Am Heart J 2003; 146: 33-41.

4. Hartmann B, Czock D, Keller F: Drug therapy in patients with chronic renal failure. Dtsch Arztebl Int 2010; 107(37): 647-56

Prof. Dr. med. Reinhard Klingel

I. Medizinische Klinik

Universitätskliniken Mainz

und Apherese Forschungsinstitut

Stadtwaldgürtel 77

50935 Köln, Germany

afi@apheresis-research.org

\section{Conflict of interest statement}

Professor Klingel has received study funding from Asahi Kasei Kuraray Medical Tokyo and Sanofi-Aventis Berlin.

\section{Antithrombotic Prophylaxis and Therapy in Renal Failure}

The authors postulate a "deep compartment" for enoxaparin. This is surprising in view of a distribution volume of some 5 liters and monophasic elimination (compare product information). Because of the structural differences of low molecular weight heparins, the pharmacokinetics of each low molecular weight heparin should be examined individually (1). Such substance specific studies in renal failure have been published for enoxaparin for a long time and have resulted in different dosage recommendations $(1,2$, product information). Unfortunately, all this was ignored in the review article. For this reason, the article's conclusions directly contradict the national and international licensing status of enoxaparin (for example, the US Food and Drug Administration [FDA]'s or the German Federal Institute for Drugs and Medical Devices [BfArM]'s).

After repeated subcutaneous administration of the prophylactic dose $(40 \mathrm{mg})$ in patients with a creatinine clearance $<30 \mathrm{~mL} / \mathrm{min}$ enoxaparin, the area under the plasma concentration time curve (AUC) is increased by an average of $65 \%$. Because of this, the prophylactic dose in patients with severely restricted renal function, according to the existing risk of thromboembolism should not be higher than $20 \mathrm{mg}$ or $30 \mathrm{mg}$. After administration of the therapeutic dose ( $1 \mathrm{mg} / \mathrm{mg} \mathrm{KG} \mathrm{b.d.)} \mathrm{in}$ severely impaired renal function, the AUC has been 
shown to double. In the product information it is therefore recommended to reduce the dose by $50 \%$. Registry data from 4687 patients with acute coronary syndrome without ST-segment elevation and moderately to severely impaired renal function imply that low molecular weight heparins (more than $80 \%$ of patients were treated with enoxaparin) result in less severe hemorrhages than treatment with unfractionated heparins (3). Especially in the situation of medication treatment in chronic renal failure, which poses particular difficulties for the treating physicians, all existing studies and the licensing status should be given enough attention when evaluating therapeutic options.

DOl: 10.3238/arztebl.2011.0112b

\section{REFERENCES}

1. Schmid P, Fischer AG, Wuillemin WA: Low-molecular-weight heparin in patients with renal insufficiency. Swiss Med Wkly 2009; 139: 438-52.

2. Darius H, Hester K, Paar WD, Sanderink GJ: Antithrombotische Therapie mit niedermolekularen Heparinen bei Niereninsuffizienz. J Kardiol 2004; 11(7-8): 313-6.

3. Collet JP, Montalescot G, Agnelli G, et al. : Non-ST-segment elevation acute coronary syndrome in patients with renal dysfunction: benefit of low-molecular-weight heparin alone or with glycoprotein IIb/Illa inhibitors on outcomes. The Global Registry of Acute Coronary Events. Eur Heart J 2005; 26: 2285-93.

4. Hartmann B, Czock D, Keller F: Drug therapy in patients with chronic renal failure. Dtsch Arztebl Int 2010; 107(37): 647-56.

\section{Dr. med. Carsten Kienitz}

Dr. med. Ludger Rosin

Prof. Dr. med. W. Dieter Paar

Sanofi-Aventis Deutschland GmbH

Potsdamer Str. 8

10785 Berlin, Germany

dieter.paar@sanofi-aventis.com

\section{Conflict of interest statement}

Dr Carsten Kienitz, Ludger Rosin MD, and Professor W Dieter Paar MD work in the medical department of Sanofi-Aventis Germany. Enoxaparin is marketed by Sanofi-Aventis Germany, P 0 Box 800860, 65908 Frankfurt/Main.

\section{Vote in Favor of Insulin}

Hartmann et al postulate that metformin should be substituted by sitagliptin in patients with an eGFR below $60 \mathrm{~mL} / \mathrm{min}$.

This recommendation is surprising - on the one hand, compensated renal failure is increasingly being challenged as a contraindication to metformin (1). In the United Kingdom, only a creatinine concentration of $>1.5 \mathrm{mg} / \mathrm{dL}$ is regarded as a contraindication. A recently published Cochrane review (2) did not find any indication that use of metformin leads to lactic acidosis more often than other antidiabetes drugs.

On the other hand the recommendation is surprising because sitagliptin is a substance about which no more is known than the fact that it lowers blood glucose concentrations. In the meantime, many reports have been received about the potential of sitagliptin to cause harm (3). A short monograph from the Drug Commission of the German Medical Association does not recommend its use in moderate or severe renal failure because not enough studies exist.

The UKPDS 34 showed that near-identical lowering of $\mathrm{HbA}_{1 \mathrm{c}}$ benefits patients to extremely varying degrees, depending on whether metformin or other substances are used. Just now, the European Medicines Agency has ord ered to take rosiglitazone off the market - another sign for the fact that lowering $\mathrm{HbA}_{1 \mathrm{c}}$ by means of medication is a very weak indicator of its use. It is not clear why the article recommends sitagliptin, a substance about which we do not know whether its use affects patient-relevant end points positively or negatively. Why did the authors not vote in favor of insulin, just in case that metformin should really not be used in more severely restricted renal function?

DOl: 10.3238/arztebl.2011.0113a

\section{REFERENCES}

1. Holstein $\mathrm{H}$, Egberts $\mathrm{E}-\mathrm{H}$ : Traditionelle Metformin-Kontraindikationen mehr Schaden als Nutzen? Dtsch Med Wochenschr 2006; 131: 105-10.

2. Salpeter SR, Greyber E, Pasternak GH: Risk of fatal and nonfatal lactic acidosis with metformin use in type 2 diabetes mellitus. The Cochrane Library 2010, Issue 1.

3. FDA: Information for Healthcare Professionals - Acute pancreatitis and sitagliptin (marketed as Januvia and Janumet), 25 Sept. 2009; http://www.fda.gov/Drugs/DrugSafety/PostmarketDrugSafetyln formationforPatientsandProviders/DrugSafetyInformationforHeathcareProfessionals/ucm183764.htm

4. Hartmann B, Czock D, Keller F: Drug therapy in patients with chronic renal failure. Dtsch Arztebl Int 2010; 107(37): 647-56.

\section{Dr. med. Günther Egidi}

Huchtinger Heerstr. 41

28259 Bremen, Germany

familie-egidi@nord-com.net

\section{Conflict of interest statement}

The author declares that no conflict of interest exists according to the guidelines of the International Committee of Medical Journal Editors.

\section{Dialysis After Administration of Gadolinium?}

In their comprehensive article, the authors present "special aspects of medication therapy in renal failure. For the suggested immediate hemodialysis after administration of gadolinium in patients with an eGFR $<30$ $\mathrm{mL} / \mathrm{min}$, a more differentiated perspective is required. The recommendation to follow gadolinium administration in an eGFR $<30 \mathrm{~mL} / \mathrm{min}$ with hemodialysis treatment relates primarily to patients who are already participating in a chronic dialysis program. To insert a central venous catheter in patients with an eGFR $<30$ $\mathrm{mL} / \mathrm{min}$ particularly to eliminate gadolinium and to follow up with dialysis does not reflect current practice nor the recommendations.

In another section, the authors warn about prescribing metformin in patients with increasingly deteriorating renal function and recommend the DPP-IVinhibitor sitagliptin for an eGFR $<60 \mathrm{~mL} / \mathrm{min}$. They recommend halving the dose in patients with an eGFR $<30 \mathrm{~mL} / \mathrm{min}$. According to product information, 
sitagliptin is not recommended in patients with an eGFR $<50 \mathrm{~mL} / \mathrm{min}$ (at least in Germany).

For completeness's sake it should be mentioned that the "calcium phosphate product" is not acknowledged in the current KDIGO guidelines for chronic kidney disease - mineral and bone disorder. The individual serum measurements of calcium and phosphate should be interpreted together and used for guiding clinical treatment. The mathematical construct of a calcium phosphate product is not explicitly recommended any more.

I doubt whether calcium-free phosphate binders such as sevelamer or lanthanum should be used only in cases of intolerance or ineffectiveness. I also doubt whether a stepwise scheme exists for administering phosphate binders. Good quality studies have shown that the efficacy of phosphate binders is similar, whether they contain calcium or not. However, aluminum-free phosphate binders should be given only temporarily, according to current guidelines. And why lanthanum should be given only temporarily does not become clear from current scientific data and existing guidelines.

DOl: 10.3238/arztebl.2011.0113b

\section{REFERENCES}

1. Hartmann B, Czock D, Keller F: Drug therapy in patients with chronic renal failure. Dtsch Arztebl Int 2010; 107(37): 647-56.

Dr. med. Fedai Özcan

Klinikum Dortmund gGmbH

Beurhausstr. 40

44137 Dortmund, Germany

Fedai.0ezcan@klinikumdo.de

\section{Conflict of interest statement}

The author declares that no conflict of interest exists according to the guidelines of the International Committee of Medical Journal Editors.

\section{The Problems of Empirical Formulas}

The frequent use of the MDRD formula to estimate the GFR should not mislead us about the fact that it is an empirical formula. This is obvious from the failure of the measurement unit calculation: The units of measurement on the right hand side do not yield the unit of measurement of the GFR $\left(\mathrm{mL} / \mathrm{min} / 1.73 \mathrm{~m}^{2}\right)$.

The MDRD formula in all its variants is the result of an estimate (regression analysis) of the ${ }^{125}$ I-iothalamate clearance by using serum concentrations of creatinine and other patient data (1). If the data of an individual patient are entered, however, the result is not his or her individual GFR but the mean GFR of the cohort under investigation at the point that corresponds to the patient's data.

The probability that this mean value is consistent with the individual GFR equals zero. The individual GFR can be captured with any certain probability only within a confidence interval. It is therefore incorrect to 0calculate using an empirical formula without confidence interval.

The problem is alleviated if the estimated GFR is not used per se but to determine a CKD stage, but it continues for the transitions between stages. Furthermore, in Table 1 the authors assigned to the CKD values GFR values with the unit of measurement $\mathrm{mL} / \mathrm{min}$ and not $\mathrm{mL} / \mathrm{min} / 1.73 \mathrm{~m}^{2}$, which means that the relation to the MDRD formula is misleading (2).

A further problem is the conversion of the GFR estimated with the MDRD formula into the absolute GFR by using the individual body surface area obtained with the Mosteller formula, - also an empirical formula (3). Mosteller did not report a confidence interval; but it can be presumed to be substantial. In the calculation, the confidence intervals of both formulas go into the end result and thus increase the uncertainty. In order to measure the absolute GFR, a clearance procedure seems to be more suitable.

DOI: 10.3238/arztebl.2011.0114a

\section{REFERENCES}

1. Levey AS, Bosch JP, Lewis JB, Green T, Rogers N, Roth D: A more accurate method to estimate glomerular filtration rate from serum creatinine: a new prediction equation. Ann Intern Med 1999; 130 461-70.

2. Hartmann B, Czock D, Keller F: Drug therapy in patients with chronic renal failure. Dtsch Arztebl Int 2010; 107(37): 647-56.

3. Mosteller RD: Simplified calculation of body-surface area. N Engl J Med 1987; 317: 1098.

Dr. med. Helmut Nocke

Institut für Physiologie

Otto-von-Guericke-Universität

Leipziger Str. 44

39120 Magdeburg, Germany

helmut.nocke@med.ovgu.de

Conflict of interest statement

The author declares that no conflict of interest exists according to the guidelines of the International Committee of Medical Journal Editors.

\section{In Reply:}

We agree with Nocke that a clearance method is desirable to measure the individual glomerular filtration rate (GFR). The MDRD2 formula, however, constitutes an enormous advance in the routine estimation of the GFR and therefore in simply establishing clinical stages of renal function.

As Özcan says, in patients with a GFR $<30 \mathrm{~mL} / \mathrm{min}$ who are not receiving dialysis it needs to be critically considered for the individual whether hemodialysis has to be performed after administration of gadolinium. Gadolinium can be dialyzed, but the clinical benefit of dialysis is unproved. In patients who did not have dialysis before, the risks and benefits of catheterization for dialysis need to be considered.

The practice of evaluating calcium and phosphate individually should not be relinquished. It does make sense, however, to start with the tested and more costeffective medications before using new preparations that are heavily advertised.

We don't think that terms such as "compensated renal failure" or referring to creatinine values is helpful in adapting dosages. Instead of the creatinine concentrations reported by Günther Egidi, of $>1.5 \mathrm{mg} / \mathrm{dl}$, we would advise not to use metformin from a defined GFR level. A "safety range" in case of renal deterioration is advisable, since lactic acidosis in patients taking 
metformin is associated with high lethality. A study with diabetes patients with renal failure (including patients with a GFR $<30 \mathrm{ml} / \mathrm{min}$ ) found that sitagliptin is sufficiently safe (1).

Enoxaparin does not have a single distribution volume - such as Paar, Kienmitz, and Rosin write, on the basis of the licensing data, but corresponding to a two-compartment pharmacokinetic it has a peripheral compartment (2). The central distribution volume is estimated to be 6.78 liters and the peripheral distribution volume at 6.19 liters. Accordingly, the terminal distribution volume can be calculated to be some 23 liters. The non-renal clearance is $0.229 \mathrm{~L} / \mathrm{h}$ and the renal clearance $0.744 \mathrm{~L} / \mathrm{h}$ in normal renal function.

From these values, the calculated half-life for the rapid elimination phase is 3 hours $\left(\mathrm{T}_{1 / 2 \alpha}\right)$ and for the slow elimination phase it is 16 hours $\left(\mathrm{T}_{1 / 2 \beta}\right)$. If repeated doses are given, the accumulation factor is much higher in the second compartment $\left(\mathrm{R}_{\beta}\right)$ than in the first compartment $\left(\mathrm{R}_{\alpha}\right)$ - an effect that increases in patients with renal failure.

Consistent with this, enoxaparin has the highest accumulation factor compared with dalteparin, nadroparin, and tinzaparin (3). It is the subject of controversy how the dosage for enoxaparin should be adjusted. Calculations have shown that if the dose is administered every 24 hours only, therapeutic gaps may occur (2). In view of recent data we do not think it is contradictory to recommend against using a medication, even though it may be formally licensed. In the prospective registry study by Collet (2005) that Reinhard Klingel cites, it seemed that for a GFR $<60 \mathrm{~mL} / \mathrm{min}$ mortality was lower in patients receiving unfractionated heparin than in those receiving enoxaparin if glycoprotein IIb/IIIa inhibitors were given simultaneously. Two studies have shown that in patients with renal failure, significantly more hemorrhages developed under enoxaparin than for unfractionated heparin or fondaparinux.

DOI: 10.3238/arztebl.2011.0114b

\section{REFERENCES}

1. Chan JC, Scott R, Arjona Ferreira JC, et al.: Safety and efficacy of sitagliptin in patients with type 2 diabetes and chronic renal insufficiency. Diabetes Obes Metab 2008; 10: 545-5.

2. Green B, Greenwood M, Saltissi D, et al.: Dosing strategy for enoxaparin in patients with renal impairment presenting with acute coronary syndromes. Br J Clin Pharmacol 2005; 59(3): 281-90.

3. Schmid P, Fischer AG, Wuillemin WA: Low-molecular-weight heparin in patients with renal insufficiency. Swiss Med Wkly 2009; 139: 438-52.

4. Hartmann B, Czock D, Keller F: Drug therapy in patients with chronic renal failure. Dtsch Arztebl Int 2010; 107(37): 647-56.

\section{Dr. med. Bertram Hartmann}

Dr. med. David Czock

Prof. Dr. med. Frieder Keller

Sektion Nephrologie, Klinik für Innere Medizin I

Zentrum für Innere Medizin

Universitätsklinikum Ulm

Albert-Einstein-Allee 23

89081 Ulm, Germany

\section{Conflict of interest statement}

Dr Hartmann has received research funding from Wyeth and Novartis and travel expenses for participating in conferences.

Professor Keller has received financial funding from Novartis, Roche Ratiopharm, TEVA, and Abbott.

Dr Czock declares that no conflict of interest exists according to the guidelines of the International Committee of Medical Journal Editors. 